\title{
Effects of bleaching agents and adhesive systems in dental pulp: a literature review
}

\author{
Maria Antonieta Veloso Carvalho de Oliveira', Paulo Sérgio Quagliatto², \\ Denildo Magalhães ${ }^{3}$, João Carlos Gabrielli Biffi ${ }^{4}$
}

\author{
'DDS, Undergraduate student, Dental School, Federal University of Uberlândia, MG, Brazil \\ ${ }^{2} \mathrm{DDS}, \mathrm{MS}, \mathrm{PhD}$, Professor of Dentistry, Dental School, Federal University of Uberlândia, MG, Brazil \\ ${ }^{3} \mathrm{DDS}, \mathrm{MS}, \mathrm{PhD}$, Professor of Periodontics, Dental School, Federal University of Uberlândia, MG, Brazil \\ ${ }^{4}$ DDS, MS, PhD, Professor of Endodontics, Dental School, Federal University of Uberlândia, MG, Brazil
}

\begin{abstract}
The dental pulp may be exposed to several irritants that are potentially noxious to the health and functions of this tissue. Each type of irritant or injury has different effects on the pulp, which are generally characterized by acute inflammation, chronic inflammation or necrosis. Common examples of irritants are dental caries, cavity preparation procedures, traumatic injuries, and chemical substances like bleaching agents and adhesive systems. The present study aimed to review the current knowledge about the effect of bleaching agents and adhesive systems in the human dental pulp. The review covered literature from 2004 to 2009, and only relevant manuscripts were included. Hand search of the references completed the review. Based on literature review, it may be concluded that all dental procedures associated with bleaching agents or adhesive systems involve risks to cause pulp damage. However, these risks can be minimized if the causal factors were known and avoided.
\end{abstract}

Keywords: adhesive systems, bleaching agents, external dental bleach, pulp response.

\section{Introduction}

The dental pulp may be exposed to wide array of irritants that are noxious to the health and functions of this tissue. Irritants can be either short-term and longterm irritating agents or trauma. Each type of irritant or injury will have different effects on the pulp, which are characterized by acute inflammation, chronic inflammation or necrosis ${ }^{1}$. The pulp develops inflammation as a basic protective biologic defense mechanism in response to any type of injury ${ }^{1-2}$. Common examples of irritants are dental caries, cavity preparation procedures, traumatic injuries, and chemical substances, like bleaching agents and adhesive systems ${ }^{1}$.

The effect of chemical substances or restorative procedures on dentin and Accepted: July 13, 2012 pulp is the result of a complex interaction among many factors such as, health of the underlying pulp, thickness and permeability of the intermediate dentin layer, mechanical injury during tooth preparation, toxicity of the restorative material and microleakage ${ }^{2}$.

The present study aimed to review the current knowledge about the effect of bleaching agents and adhesive systems in the human dental pulp. The review covered literature from 2004 to 2009 and only relevant papers were included. Hand search of the references completed the review. The search used PubMed 
electronic full-text database with the terms "bleaching agents", "external dental bleach", "adhesive systems" and "pulp response".

\section{Bleaching agents}

Tooth bleaching is one of the most common procedures currently performed in contemporary dentistry. Some controversy still exists on the safety of the tooth bleaching. Several studies have defended that this procedure is innocuous to dental tissues, but there is evidence in the literature that the chemicals used for tooth bleaching have deleterious effects on the pulp-dentin complex ${ }^{3}$.

The most commonly used chemicals for tooth bleaching usually contain some form of hydrogen peroxide $\left(\mathrm{H}_{2} \mathrm{O}_{2}\right)$ at different concentrations. $\mathrm{H}_{2} \mathrm{O}_{2}$ is an oxidant agent that, with the aid of some chemical or physical activators (i.e., enzymes, light or heat), dissociates in perhydroxyl and oxygen radicals. These free radicals, known as reactive oxygen species, have low molecular weight and are able to denaturize proteins ${ }^{3-4}$, creating porosities on the enamel structure that can permit the diffusion through the organic matrix of dentine $e^{5-7}$. The diffusion of $\mathrm{H}_{2} \mathrm{O}_{2}$ through dentin depends on the original concentration of the bleaching agent and the length that the agent is in contact with the dentin ${ }^{3-4,8}$. Other factors such as positive pulp pressure and osmotic pressure of the gels, and application of heat during bleaching procedure might have influence on the diffusion of peroxides to the pulp ${ }^{8}$. The presence of dentinal tubules within the tooth architecture could allow these free radicals to reach the pulp tissue and generate adverse effects ${ }^{3-5}$. A recent study simulated a professionally applied vital tooth bleaching procedure with $35 \% \mathrm{H}_{2} \mathrm{O}_{2}$ bleaching gel, and showed that the diffusion of the bleaching gel components through enamel and dentin caused severe toxic effects to the cultured pulp cells ${ }^{5}$.

The potential adverse effects of $\mathrm{H}_{2} \mathrm{O}_{2}$ on the oral tissues have been widely investigated, especially because it is a thermally unstable chemical agent with a high oxidative power, which may dissociate into water, oxygen and some free radical species, such as hydroxyl radicals $(\mathrm{OH})$. The oxidative reactions and consequently the cell damage caused by free radicals are the main mechanisms responsible for the toxicity of peroxide-containing compounds ${ }^{9}$. Chemical reactions can be increased by increasing the temperature, where a $10{ }^{\circ} \mathrm{C}$ rise can double the rate of reaction ${ }^{10}$. The use of light and/or heat-activated tooth bleaching systems generates an increased reaction of $\mathrm{H}_{2} \mathrm{O}_{2}$ with an accelerated release of free radicals, which is clinically translated into a faster whitening effect ${ }^{3}$. However, there is a significant increase in the intrapulpal temperature and in the diffusion of bleaching gel components to the pulp, causing an increase in pulpal inflammatory reaction ${ }^{3,9}$. Previous studies using different light sources demonstrated that differences in temperature changes depend on the type of light employed ${ }^{11}$ and may be critical $^{12}$ or not ${ }^{11}$ for pulpal health. The bleaching gel usually applied may act as an isolator reducing intrapulpal temperature rise as compared to activated bleaching performed without gel application ${ }^{11-13}$. This means that laser activation without the use of bleaching gel results in an intrapulpal temperature increase of about $16^{\circ} \mathrm{C}$, whereas a $8.7^{\circ} \mathrm{C}$ temperature increase was recorded when a gel was applied during activation. Temperature increase may also depend on amount and type of color pigments included on the gels ${ }^{11}$. Nowadays, an intrapulpal temperature increase of $5.5 æ \% \mathrm{C}$ is regarded as the threshold value, which should not be exceeded to avoid irreversible thermal pulp damage ${ }^{11-14}$. Most bleaching lamps do not raise the pulpal temperature to dangerous levels. However, care should be taken when using laser lamps at high power settings ${ }^{11}$ (e.g. above $2 \mathrm{~W}^{12}$ ).

Composite resins are the most common material used for esthetic restoration of anterior teeth and most patients seeking for whither teeth have restoration. The studies that investigated the effect of bleaching agents on the restorative materials were developed mainly to evaluate if bleaching materials could exert any influence on the physicochemical properties, and on the release of monomers from the composite materials. Polydouro et al. ${ }^{15}$ observed that bleaching of composite fillings can result, in some cases, in less monomer release from composite materials. Therefore, the contact of bleaching agents with composite materials may not have any detrimental results for the human health due to an increased monomer release caused by bleaching ${ }^{15}$. The capacity of $\mathrm{H}_{2} \mathrm{O}_{2}$ to diffuse through the pulp chamber in vitro was evaluated in teeth following restorative procedures ${ }^{4}$. Restored teeth had significantly higher $\mathrm{H}_{2} \mathrm{O}_{2}$ concentrations in the pulp chamber that intact teeth. According to the authors, this occurs due to the microleakage around the restorative materials. Moreover, restorations margins can be considered a possible pathway for $\mathrm{H}_{2} \mathrm{O}_{2}$ penetration into the pulp chamber ${ }^{4}$. The penetration of peroxides into the pulp chamber of restored teeth depends of the type of the restorative material, being higher in teeth restored with resin-modified glass ionomer cements ${ }^{7}$.

The majority of studies that evaluates tooth whitening process involve the use of either $\mathrm{H}_{2} \mathrm{O}_{2}$ or carbamide peroxide. In contact with water, carbamide peroxide breaks down into urea and $\mathrm{H}_{2} \mathrm{O}_{2}{ }^{10}$. Urea may contribute to the structural changes and roughness of enamel. However, it can promote beneficial side-effects because the alkaline property of urea raises the hydrogen ion concentration $(\mathrm{pH})$ of the bleaching solution and reduces the adverse effects in pulp tissue ${ }^{6}$.

Today, tooth bleaching has moved out of the dental office into the patient's home. Generally, a soft, custom-made, plastic tray filled with a bleaching gel is used for home bleaching. Recently, a new vital tooth whitening technique, using flexible strips that are applied directly to the tooth, was introduced. These strips contain various concentrations of $\mathrm{H}_{2} \mathrm{O}$ and eliminate the need for custom-made trays for each patient. This bleaching technique was studied to evaluate the $\mathrm{H}_{2} \mathrm{O}_{2}$ penetration containing $6.5 \%$ and $14 \% \mathrm{H}_{2} \mathrm{O}_{2}$ in the pulp chamber of the teeth. On the basis of the results and within the limitations of the in vitro study, the authors concluded that $\mathrm{H}_{2} \mathrm{O}_{2}$ from whitening strips readily penetrates into the pulp chamber at various amounts and further studies are necessary to evaluate its clinical performance ${ }^{8}$. 
Although the findings of in vitro studies have clinical relevance, the results of laboratory $\mathrm{H}_{2} \mathrm{O}_{2}$ diffusion experimental models might not predict the real penetration capacity of this chemical agent in vivo ${ }^{10}$. In laboratory experimental models, the absence of the outward intradentinal fluid flow might contribute to the rapid diffusion of bleaching gel components through dentin. The presence of a dentinal fluid flow produced by intrapulpal pressure in vital teeth is sufficient to substantially reduce the diffusion of chemicals into the dentinal tubules to reach the pulp ${ }^{4-5,8}$. Therefore, as stated by Gokay et al. ${ }^{8}$, it is possible to assume that the levels of $\mathrm{H}_{2} \mathrm{O}_{2}$ or the byproducts of its degradation that reach the pulp tissue in vivo may actually be lower than those observed in ex vivo experiments.

\section{Adhesive systems}

Contemporary dental adhesive systems are used to improve the contact between composite restorative materials and the walls of the prepared tooth cavity. As these materials come in close and prolonged contact with vital dentin, their influence on pulp tissue is critical ${ }^{16}$.

Histopathology studies have indicated that adhesive resins elicit transient, inflammatory changes and irregular dentin formation of the dental pulp at short-term evaluations. These pulp inflammatory responses are most likely due to irritation by diffusible dentin bonding ingredients released following light curing, especially when the remaining dentin thickness is thin or pulp exposure is noted during cavity preparation ${ }^{2}$. The composition of dentin adhesive is one of the factors that influence pulp response to dentin adhesives ${ }^{2,17-18}$.

Polymerized adhesives materials could release residual monomers that may interact with pulp tissues ${ }^{16}$. Some monomers are associated to cytotoxic effects on fibroblast and odontoblastslike cells, such as Bis-GMA, HEMA, UDMA, TEGDMA ${ }^{18-20}$. All these components, individually or in combination, ultimately compromise the pulp healing. The main constituents of primer and adhesive solution are HEMA and Bis-GMA, respectively. In a ranking of toxicity, HEMA is the least toxic substance compared to other monomers such as Bis-GMA, UDMA and TEGDMA after 24 and $72 \mathrm{~h}$ of exposure ${ }^{18}$. The high percentage of HEMA in the primer, its lack of polymer conversion due to the absence of photoinitiators, its low molecular weight and hydrophilic features, facilitate its diffusion through pulp tissue and consequently avoid pulp healing ${ }^{18-19}$. Moreover, HEMA diffusion was found in young and old primary teeth ${ }^{17}$. BisGMA shows higher cytotoxic effects than HEMA. Consequently, one may suggest that the high concentration of HEMA and Bis-GMA present in the primers and adhesive resins may cause remarkable cytopathic effects and elicit severe inflammatory response when applied in contact to connective tissue ${ }^{21}$.

After acid etching, a significant increase in dentin permeability due to smear layer removal and opening of dentinal tubules can facilitate the permeation of resin monomers towards pulp, mainly in deep dentin ${ }^{17,19}$. Odontoblasts are typical pulp cells and are the first cells to be damaged by potentially cytotoxic compounds released from dental materials that diffuse through enamel and dentinal tubules ${ }^{18,20,22}$. Injury to the odontoblasts results in loss of the capacity of these cells to secrete reactionary dentin, and secretion of dentin bridge by a new generation of odontoblasts-like cells $\mathrm{s}^{22-23}$.

The cytotoxic potential demonstrated by the dental adhesives might be of clinical relevance, since all dental adhesives disturb the cellular redox state of pulp cells in monolayer cultures. Demirci et al. ${ }^{16}$ suggested that the concentrations of biologically active ingredients of some of the bonding agents may be high enough to modify pulp cell metabolism when the materials are used into deep cavities or even in directly contact with the pulp tissue. Teixeira et al. ${ }^{21}$ evaluated in vivo the biocompatibility of adhesive systems and the bonding agent that contained UDMA on its chemical composition, presented high cytopathic effects interfering with the cellular cycle in pulp tissue.

A chronic inflammatory response may be directly related to the cytotoxic effects of the bonding agent's components, the accumulation of its fragments in the pulp during the procedure may evoke this persistent reaction ${ }^{24}$. Self-etching priming solutions contain larger amounts of acidic monomers to produce an etching effect for enamel and dentin. The acidic characteristics of the adhesive may be retained and, thus, continue to affect dentin and consequently the pulp. Onestep self-etch adhesive systems induce inflammatory reactions of the pulp. It seems evident that application of this adhesive on prepared teeth has a potential to interfere with early stage of inflammatory response in dental pulp ${ }^{2}$. The acid etchants of the total-etch three-step adhesive systems contain other components, which are shared between the primer and adhesive bottles. All different components present in the total-etch threestep adhesive system, individually or in combination, may result in degenerative pulp alterations when placed directly onto pulp exposure sites ${ }^{19}$. An evaluation of the cytotoxic effect of total-etch two-step adhesive systems showed that both the acidic and non-acidic components of unpolymerized adhesive resins were responsible for high cytotoxic effects on odontoblast-like cells ${ }^{25}$. In another study where two self-etch adhesive systems were evaluated, the pulp tissue exhibited moderate to severe inflammatory cell infiltrate involving the coronal pulp with chronic abscesses ${ }^{26}$. The difference in toxic behavior between the total-etch and self-etch systems has been attributed to the fact that the total-etch systems they involve the use of phosphoric acid, which completely remove the smear layer and smear plugs, while enlarging the lumen of the dentinal tubules by the dissolution of the peritubular dentin, favoring the transdentinal diffusion of various substances, including those undesirable from the toxicological perspective ${ }^{20}$. Also, self-etch agents are less acidic than the phosphoric acid, reducing their deleterious potential over the pulp tissue ${ }^{27}$. Furthermore, the use of selfetch adhesives systems is indicated for young, deep, permeable dentin because self-etch adhesives often leave some residual smear plug material in the tubules which limits the diffusion of uncured monomers toward the pulp ${ }^{18}$.

The degree of cytotoxicity depends on the concentration of the material used and the monomers may have synergistic 
or antagonistic cytotoxic effects. Resinous monomers are cytotoxic at high concentrations, and they seem to provoke specific effects on pulp cells at low concentrations. The nontoxic concentrations of monomers may reduce the mitochondrial activity of pulp macrophages and the process of mineralization ${ }^{23}$. According to Lanza et al. ${ }^{20}$, it could be suggested that the toxicity of adhesive materials depends on their chemical characteristics and the concentrations at which their components reach the pulp tissue rather than their capacity to dissolve the smear layer and demineralize the subjacent dentin.

Photoactivation of monomers in the bonding agents applied to dentin may neutralize their negative effects on the differentiation of human pulp cells into odontoblasts in vitro $^{23}$. When monomers are photoactivated, the amount of unreacted products leached out is reduced and thus their cytotoxic effects to the cells are dramatically diminished ${ }^{18,26}$. This is of key importance in restorative dentistry particularly in the restoration of deep cavity where odontoblastic differentiation from pulp fibroblasts is a critical step in hard tissue secretion and pulp healing ${ }^{23}$. It is important to take into consideration that the residual water present in the hybrid layer and the dentin tubules may result in poor monomer-topolymer conversion and increase of monomer release ${ }^{17}$.

Another factor that has some impact on the severity of pulp response is the remaining dentin thickness or proximity of the injury stimulus to the pulp tissue: the thinner the dentin, the more severe the pulp inflammation ${ }^{16,18,23,28}$. A remaining dentin thickness of more than $0.5 \mathrm{~mm}$ is necessary to avoid causing any evidence of pulp injury ${ }^{17,28}$ About et al. ${ }^{23}$ concluded in their study that dentin bonding agents do not affect the cytodifferentiation of secondary odontoblasts when the remaining dentin thickness is 0.7 $\mathrm{mm}$ and when the materials are properly polymerized. On the other hand, the authors showed that the direct contact of uncured monomers affect the differentiation of odontoblasts from pulp fibroblasts and the process of mineralization $^{23}$. The monomers in deep cavities may possibly reach the dental pulp in concentrations that disturb the redox state of pulp cells. The production of reactive oxygen species by these monomers has been related to the induction of cell death via apoptosis. The dentin works as an effective barrier, preventing cell damage from a great variety of materials and chemicals ${ }^{16}$.

The advent of adhesive dentistry has broadened the range of possibilities of using resin-based materials for a wide variety of clinical applications in dentistry. Amongst them, the possibility of direct pulp capping with bonding agents has increased ${ }^{19}$. Dentin bonding agents have been examined as potential direct capping materials because of their superior ability to adhere to both demineralized enamel and dentin tissues ${ }^{24,29}$. Hybridization of these agents with demineralized intertubular collagen as well as the diffusion of adhesives into the dentin tubules may seal the vital dentin against bacterial leakage and reduce secondary pulpal inflammation. However, in vitro studies have shown that acid etchants, monomers, and other ingredients in the composition of various adhesive systems can be toxic ${ }^{29}$ to nerves, cytotoxic to cultured cell lines, and mutagenic to microorganisms and mammalian cells $^{24}$. According to an in vivo study ${ }^{30}$, when dentin adhesive systems are applied in direct contact with mechanically exposed pulp of healthy dog teeth acceptable repair of the dentin-pulp complex is not expected, such as wound healing with tertiary dentin bridge formation. Therefore adhesive components (primer or adhesive) and composite resin should be avoided for pulp capping ${ }^{19,24,26,30}$. Adverse tissue reactions to adhesive systems placed in direct contact with the pulp tissue might also be attributed to the presence of resin particles in the pulp space, triggering a foreign body response, or to the heat originated during light curing ${ }^{30} \cdot \mathrm{Ca}(\mathrm{OH})_{2}$, should be the first choice for pulp capping ${ }^{19,29}$, which demonstrated biocompatibility in cement and dry powder forms ${ }^{29}$.

\section{Final considerations}

The dental pulp is a unique tissue and its role is of great importance in the long-term prognosis of the teeth. Clinicians must have a thorough understanding of the biological consequences of treatment interventions in this tissue.

Although the literature reports limited to reversible effects of defensive mechanisms of pulp against irritation caused by bleaching agents, careful manipulation is needed in the use of this material. Another consideration is that although recent studies indicate that the risks of acute pulp toxicity to adhesive systems are unlikely to occur, it is clear that contemporary existing tests are not adequate to predict long-term clinical biological risks.

Based on this literature review including papers published over the last five years, it may be concluded that all dental procedures with bleaching agents or adhesive systems involve risks to cause pulp damage, but these risks can be minimized if the causal factors are known and avoided.

\section{References}

1. Yu C, Abbott PV. An overview of the dental pulp: its functions and responses to injury. Aust Dent J Endod. 2007; 52(1 Suppl): S4-16.

2. Bagis B, Atilla P, Cakar N, Hasanreisoglu U. Immunohistochemical evaluation of endothelial cell adhesion molecules in human dental pulp: Effects of tooth preparation and adhesive application. Arch Oral Biol. 2007; 52: 705-11.

3. Caviedes-Bucheli J, Ariza-Garcia G, Restrepo-Méndez S, Rios-Osorio $N$, Lombana N, Muñoz HR. The effect to tooth bleaching on substance $P$ expression in human dental pulp. J Endod. 2008; 34: 1462-5.

4. Benneti AR, Valera MC, Mancini MNG, Miranda CB, Baldicci I. In vitro penetration of bleaching agents into the pulp chamber. Int Endod J. 2004; 37: $120-4$

5. Trindade FZ, Ribeiro APD, Sacono NT, Oliveira CF, Lessa FCR, Hebling $\mathrm{J}$ et al. Trans-emanel and trans-dentinal cytotoxic effects of $35 \% \mathrm{H} 2 \mathrm{O} 2$ bleaching gel on cultured odontoblast cell lines after consecutive applications. Int Endod J. 2009; 42: 516-24.

6. Cavalli V, Arrais CAG, Giannini M, Ambrosano GMB. High-concentration carbamide peroxide bleaching agents on enamel surface. J Oral Rehabil. 2004: 31: 155-9

7. Camargo SEA, Valera MC, Camargo CHR, Mancini MNG, Menezes MM. Penetration of $38 \%$ hydrogen peroxide into the pulp chamber in bovine and human teeth submitted to office bleach technique. J Endod. 2007; 33: 1074-7. 


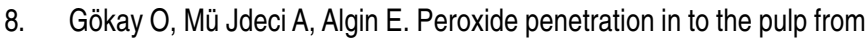
whitening strips. J Endod. 2004; 30: 887-9.

9. Kawamoto $K$, Tsujimoto $Y$. Effect of the hydroxyl radical and hydrogen peroxide on tooth bleaching. J Endod. 2004; 30: 45-50.

10. Joiner A. The bleaching of teeth: a review of the literature. J Dent. 2006; 34: 412-9.

11. Sulieman M, Addy M, Rees JS. Surface and intra-pulpal temperature rises during tooth bleaching: an in vitro study. Br Dent J. 2005; 199: 37-40.

12. Sulieman M, Addy M, Rees JS. Surface and pulp chamber temperature rises during tooth bleaching using a diode laser: a study in vitro. Br Dent $\mathrm{J}$. 2006; 200: 631-4.

13. Buchalla W, Attin T. External bleaching therapy with activation by heat, light or laser - a systematic review. Dent Mater. 2007; 23: 586-96.

14. Zach L, Cohen G. Pulp response to externally applied heat. Oral Surg Oral Med Oral Pathol. 1965; 19: 515-30.

15. Polydorou O, Beiter J, König A, Hellwig E, Kümmerer K. Effect of bleaching on the monomers from modern dental composite material. Dent Mater. 2009; 25: 254-60.

16. Demirci M, Hiller K-A, Galler K, Schmalz G, Schweikl H. The induction of oxidative stress, cytotoxicity, and genotoxicity by dental adhesives. Dent Mater. 2008; 24: 362-371.

17. Çetingüç $A$, Ölmez $S$, Vural N. HEMA diffusion from dentin bonding agents in young and old primary molars in vitro. Dent Mater. 2007; 23: 302-7.

18. Bouillaguet S. Biological risks of resin-based materials to the dentin-pulp complex. Crit Rev Oral Biol Med. 2004; 15: 47-60.

19. Accorinte MLR, Loguercio AD, Reis A, Muench A, Araújo VC. Adverse effects of human pulp after direct pulp capping with the different components from a total-etch, three-step adhesive system. Dent Mater. 2005; 21: 599-607.

20. Lanza CRM, Costa CAS, Furlan M, Alécio A, Hebling J. Transdentinal diffucion and cytotoxicity of self-etching adhesive systems. Cell Biol Toxicol. 2009; 25: 533-43.

21. Teixeira HM, Do Nascimento ABL, Hebling J, Costa CAS. In vivo evaluation of the biocompatibility of three current bonding agents. J Oral Rehabil. 2006; 33: 542-50.

22. Goldberg M, Smith AJ. Cells and extracellular matrices of dentin and pulp: a biological basis for repair and tissue engineering. Crit Rev in Oral Biol Med. 2004; 15: 13-27.

23. About I, Camps J, Burger A-S, Mitsiadis WT, Franquin J-C. Polymerized bonding agents and the differentiation in vitro of human pulp cells into odontoblast-like cells. Dent Mater. 2005; 21: 156-63.

24. Sübay RK, Demirci M. Pulp tissue reactions to a dentin bonding agent as a direct capping agent. J Endod. 2005; 31: 201-4.

25. Costa CAS, Vaerten MA, Edwars CA, Hanks CT. Cytotoxic effects of current dental adhesive systems on immortalized odontoblast cell line MDPC-23. Dent Mater. 1999; 15: 434-41.

26. Accorinte MLR, Loguercio AD, Reis A, Costa CAS. Response of human pulps capped with different self-etch adhesive systems. Clin Oral Invest. 2008; $12:$ 119-27.

27. Kenshima S, Reis A, Uceda-Gomez N, Tancredo L de L, Filho LE, Nogueira FN, Loguercio AD. Effect of smear layer thickness and $\mathrm{pH}$ of self-etching adhesive systems on the bond strength and gap formation to dentin. J Adhes Dent. 2005; 7: 117-26.

28. Murray PE, Smith AJ, Windsor LJ, Mjör IA. Remaining dentine thickness and human pulp responses. Int Endod J. 2003; 36: 33-43.

29. Cavalcanti BN, Rode SM, Marques MM. Cytotoxicity of substances leached or dissolved from pulp capping materials. Int Endod J. 2005; 38 : 505-9.

30. Koliniotou-Koumpia E, Tziafas D. Pulpal responses following direct pulp capping of healthy dog teeth with dentine adhesive systems. J Dent. 2005; 33: 639-47. 